\title{
Penentuan Kelayakan Fungsi untuk Pemodelan Pemanasan Minyak Mentah menggunakan Energi Gelombang Mikro
}

\author{
Yustiana, ${ }^{*}$ Melania Suweni Muntini, dan Yono Hadi Pramono \\ Jurusan Fisika, Fakultas Matematika dan Ilmu Pengetahuan Alam, \\ Institut Teknologi Sepuluh Nopember (ITS), Kampus ITS Sukolilo, Surabaya 60111
}

\begin{abstract}
Intisari
Tingginya kebutuhan supply energi menuntut terus dikembangkannya teknologi pengolahan minyak bumi. Salah satu proses penting di dalam pengolahan minyak bumi adalah proses pemanasan, yang secara konvensional dapat mereduksi hasil produksi minyak bumi. Penelitian ini bertujuan untuk membuat pemodelan pemanasan minyak mentah menggunakan energi gelombang mikro di dalam suatu pipa sumur minyak. Teknik pemanasan ini selain bertujuan untuk menurunkan viskositas dan mengurangi jumlah partikel residu, juga untuk meminimalkan biaya produksi. Data sekunder yang diperoleh kemudian dimodelkan dan dianalisa menggunakan parameter NSD (Normalisasi Square Deviation) untuk menentukan kelayakan fungsi. Hasil yang diperoleh bahwa leyakan fungsi untuk pemodelan menunjukkan bahwa temperatur minyak dari permukaan pipa sampai dengan kedalaman sumur menurun secara eksponensial. Temperatur minyak dari pusat silinder sampai ke tepi pipa menurun secara sinusoidal. Untuk sumber gelombang mikro dengan daya $500 \mathrm{~W}$ dan waktu $10 \mathrm{~s}$ dihasilkan temperatur maksimum $385^{\circ} \mathrm{C}$.
\end{abstract}

\begin{abstract}
Due to the high demand of energy supply, a development in petroleum processing technology is required. One of the important processes in the petroleum processing is the heating process, which conventionally can reduce the oil production. This study aims to create a real-time modeling of crude oil heating process using microwave energy in an oil well pipe. In addition, this heating technique aims to reduce the viscosity and reduce the amount of residual particles, as well as to minimize the production cost. The secondary data were obtained, and subsequently being modeled and analyzed using NSD parameter (Normalized Square Deviation) to determine the feasibility of the function. Modeling results indicate that the temperature of the oil from the surface to the depth of the well pipe decreases exponentially. While the oil temperature from the center to the edge of the cylindrical pipe decreases sinusoidally. The microwave source has a power of $500 \mathrm{~W}$ and a maximum temperature produced of $385^{\circ} \mathrm{C}$ in $10 \mathrm{~s}$.
\end{abstract}

KATA KUNCI: pemodelan, minyak mentah, pemanasan, energy gelombang mikro,kelayakan model.

\section{PENDAHULUAN}

Secara umum terjadinya peningkatan kebutuhan energi berkaitan erat dengan peningkatan kegiatan ekonomi dan pertambahan jumlah penduduk. Di Indonesia, jumlah penduduk yang mengalami peningkatan dari tahun ke tahun dan pertumbuhan ekonomi terus berlangsung dengan ditunjukkannya beragam aktivitas ekonomi, maka peningkatan kebutuhan energi baik pada sektor industri maupun transportasi merupakan suatu hal yang tidak bisa dihindari [1].

Sementara jumlah cadangan energi, khususnya energi fosil sangat terbatas. Cadangan dan produksi minyak di Indonesia terus mengalami penurunan yang disebabkan oleh dua hal utama.Pertama, eksploitasi minyak selama bertahun-tahun,

\footnotetext{
${ }^{*}$ E-MAIL: yustianaramadhani@ymail.com
}

dan kedua karena minimnya eksplorasi atau survey geologi untuk menemukan cadangan minyak terbaru. Sedangkan penurunan produksi minyak disebabkan sumur-sumur yang ada sudah tua, teknologi yang digunakan sudah ketinggalan [2].

Di pihak lain, wacana tentang sumber energi terbarukan masih bertahan pada tahap menyiapkan peraturan tentang mengurangi ketergantungan pada sumber bahan bakar minyak. Sehingga sumber energi berbahan fosil masih menjadi kebutuhan utama. Oleh sebab itu diperlukan adanya inovasi-inovasi teknologi baru untuk meningkatkan produksi minyak bumi melalui efisiensi atau optimasi proses di dalam industri perminyakan.

Selama ini pada sejumlah industri pengeboran minyak bumi masih menggunakan metode konvensional seperti steam injection, yaitu proses pemanasan yang berasal dari pembakaran bahan bakar fosil untuk memenuhi kebutuhan energi pada proses pengilangan minyak bumi.Pemanasan ini bertujuan un- 
tuk menurunkan viskositas minyak agar mudah dialirkan. Namun hasilnya masih kurang efektif dibandingkan dengan biaya yang dibutuhkan untuk sumur produksi karena faktor heat loss [3].

Sebagai inovasi diusulkan energi gelombang mikro menjadi salah satu alternatif pengganti energi pada proses pemanasan minyak di dalam sumur produksi. Radiasi gelombang mikro dengan pembangkit magnetron akan diserap oleh minyak mentah sesuai dengan besar sifat dan loss dielektriknya, kemudian diubah menjadi energi panas. Energi panas ini akan meningkatkan suhu crude oil dan menurunkan nilai viskositas sehingga lebih mudah untuk dialirkan. Hal lain yang menjadi kelebihan energi gelombang mikro ini adalah proses pemanasannya yang bersifat volumetrik, lebih cepat, efektif, dan efisien [4].

Sahni, et al. [5] dalam penelitiannya mendiskusikan metode alternatif transfer panas pada reservoir minyak berat menggunakan gelombang elektromagnetik. Reservoir dengan permeabilitas sangat rendah dan kekentalan minyak sedang, dipanaskan menggunakan antenna microwave pada frekuensi 0,915 GHz yang diletakkan didekat producing well, di bagian terendah pada jarak 30 kaki dari sumur produksi dengan daya yang bervariasi dari 30, 45, dan $60 \mathrm{~kW}$. Hasilnya, simulasi menggunakan simulator TERASING menunjukkan bahwa suhu di dekat sumber microwave meningkat sekitar $400^{\circ} \mathrm{F}$ $\left(300^{\circ} \mathrm{F}\right.$ melebihi keadaan awal $\left.100^{\circ} \mathrm{F}\right)$ dan penurunan viskositas dari $33 \mathrm{cp}$ menjadi $0,33 \mathrm{cp}$.

Sementara, Bjordalen [6] juga melakukan riset tentang pengaruh irradiasi gelombang mikro dan ultrasonic untuk menghilangkan endapan paraffin dan aspal pada sumur horizontal. Microwave digunakan memindah dan merubah arah plumb untuk membersihkan daerah terkontaminasi. Digunakan 3 sampel destilasi air dicampur dengan komposisi ( $0 \%$, $10 \%$, dan $100 \%$ ) minyak mentah, paraffin dan aspal masingmasing sebanyak $50 \mathrm{ml}$, kemudian sampel diradiasi dibawah paparan gelombang mikro. Hasilnya adalah irradiasi microwave meningkatkan suhu minyak mentah, menurunkan viskositas, serta mengurangi jumlah partikel yang mengendap, yaitu paraffin dan aspal, karena keduanya menguap jika suhunya meningkat.

Untuk mendapatkan suatu bahan bakar yang bisa langsung digunakan untuk kebutuhan sehari-hari, minyak mentah harus dipanaskan terlebih dahulu sampai pada batas temperatur dan titik didih tertentu. Oleh sebab itu dibutuhkan energi yang dapat memanaskan minyak, sampai minyak dapat mengalir dari dalam pipa-sumur minyak sesuai dengan viskositas yang dikehendaki.

Persamaan aliran atau perambatan panas pada fluida karena paparan gelombang mikro (insident wave) mengubah energi gelombang elektromagnetik menjadi energi panas adalah sebagai berikut [7]

$$
\frac{\partial T}{\partial t}+\vec{\nu} \nabla T=\frac{k}{\rho C_{p}} \nabla^{2} T+\frac{Q}{\rho C_{p}}
$$

yang menyatakan laju perubahan temperatur pada setiap titik posisi dan waktu pada suatu fluida karena pengaruh energi gelombang elektromagnetik, dalam penelitian ini adalah gelombang mikro. $\rho, \mathrm{C}_{p}, \mathrm{k}, \mathrm{T}$, dan $\mathrm{Q}$ masing-masing adalah

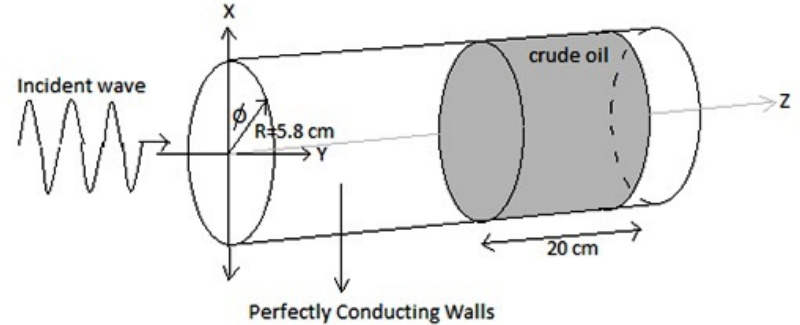

Gambar 1: Model analitis.

kerapatan, kalor jenis, konduktivitas termal, temperatur dan pembangkit panas elektromagnetik lokal yang merupakan fungsi medan listrik dan didefinisikan sebagai

$$
Q=2 \pi f \epsilon_{\circ} \epsilon_{r}(\tan \delta)|E|^{2}
$$

dengan $\epsilon=\epsilon_{\circ} \epsilon_{r}$, dan $\epsilon_{\circ}=8.854 \mathrm{pFm}^{-1}$ adalah permitivitas pada ruang bebas, dan $\epsilon_{r}$ adalah konstanta dielektrik relatif bahan, $\tan \delta$ adalah lossfaktor dielektrik, $\mathrm{E}^{2}$ adalah amplitudo medan listrik.

Sementara persamaan aliran fluida pada koordinat silinder mengikuti solusi persamaan Navier-Stoke, melalui deskripsi keseimbangan momentum dan kontinuitas dituliskan sebagaimana diberikan oleh [7]:

persamaan kontinuitas

$$
\nabla \cdot \vec{\nu}=0
$$

persamaan momentum

$$
\rho \frac{\partial \nu}{\partial t}=-\nabla p+\eta\left(\nabla^{2} \nu\right)+\rho g
$$

dengan persamaan ini menggambarkan kecepatan pemanasan fluida dengan $\eta$ adalah viskositas fluida, g dan $\mathrm{p}$ adalah gravitasi dan tekanan.

Secara umum studi tentang pemanas gelombang mikro berkaitan dengan solusi propagasi persamaan gelombang elektromagnetik, yaitu persamaan Maxwell dan gabungan antara persamaan panas dan momentum. Gambar 1, menunjukkan model analitis dengan pandu gelombang silinder.

Persamaan gelombang elektromagnetik Maxwell yang digunakan adalah sebagai berikut:

$$
\begin{aligned}
\nabla \times E & =-\mu \frac{\partial H}{\partial t} \\
\nabla \times H & =\sigma E+\epsilon \frac{\partial E}{\partial t} \\
\nabla \bullet E & =\frac{q}{\epsilon} \\
\nabla \bullet E & =0
\end{aligned}
$$

dengan $\mathrm{E}$ dan $\mathrm{H}$ adalah medan listrik dan medan magnetik, $\sigma$ adalah konduktivitas listrik, $\mu$ adalah permeabilitas magnit dan $\epsilon$ adalah permitivitas listrik.

Fluks energi diasosiasikan pada propagasi gelombang elektromagnetik, direpresentasikan oleh vektor Pointing berikut

$$
S=\frac{1}{2} R_{e}(E \times H)
$$


Teorema pointing ini mengikuti evaluasi input daya gelombang mikro dan diekspresikan sebagai:

$$
P_{\text {in }}=\int S d A=\frac{A}{4 Z_{H}} E_{\text {in }}^{2}
$$

Digunakan pandu gelombang silindrik dengan gelombang elektromagnet merambat pada arah sumbu Z, maka medan magnet dan medan listriknya akan merupakan pemecahan gelombang elektromagnetik melalui solusi persamaan Bessel. Maka solusi medan listrik dan medan magnet untuk modus TE $\left(E_{z}=0, H_{z} \neq 0\right)$ dan modus TM $\left(\mathrm{E}_{z} \neq 0, \mathrm{H}_{z}=0\right)$ adalah [8]

$$
\begin{aligned}
& E_{z}=E_{0 z} \cos n \phi J_{n}\left(k_{e} r\right) e^{-j \beta_{g} z} \\
& H_{z}=H_{0 z} \cos n \phi J_{n}\left(k_{e} r\right) e^{-j \beta_{g} z}
\end{aligned}
$$

dengan $\beta_{g}$ untuk modus TM dan TE masing-masing adalah

$$
\begin{aligned}
& \beta_{g}=\sqrt{\omega^{2} \mu \epsilon-\left(\frac{x_{n p}}{a}\right)^{2}} \\
& \beta_{g}=\sqrt{\omega^{2} \mu \epsilon-\left(\frac{x_{n p}^{\prime}}{a}\right)^{2}}
\end{aligned}
$$

dengan $\mathrm{k}_{n p}=\frac{x_{n p}}{a}$ untuk modus TM dan $\mathrm{k}_{n p}=\frac{x_{n p}^{\prime}}{a}$ untuk modus TE, dengan $\mathrm{x}_{n p}$ dan $\mathrm{x}_{n p}^{\prime}$ adalah pembuat nol fungsi Bessel, a adalah jari-jari. Frekuensi ambang (cut-off frequency) untuk modus TM dan TE masing-masing adalah

$$
\begin{aligned}
& f_{c o}=\frac{x_{n p}}{2 \pi a \sqrt{\mu \epsilon}} \\
& f_{c o}=\frac{x_{n p}^{\prime}}{2 \pi a \sqrt{\mu \epsilon}}
\end{aligned}
$$

Telah diketahui bahwa sifat dielektrik sangat penting untuk prediksi secara teori. Energi disipasi gelombang mikro merepresentasikan energi absorbsi yang diubah dalam bentuk energi panas pada bahan dielektrik. Pada saat yang sama temperatur akan dihasilkan dengan perubahan sifat dielektrik [9].

Untuk fluida minyak (oil-water emulsi) ekspresi efektif dielektrik menurut Fricke [4] adalah

$$
\kappa^{*}=\kappa_{C}^{*} \frac{\kappa_{D}^{*}(1+a \phi)+\kappa_{C}^{*} a(1-\phi)}{\kappa_{C}^{*}(a+\phi)+\kappa_{D}^{*}(1-\phi)}
$$

dengan $\kappa_{C}^{*}$ dan $\kappa_{D}^{*}$ adalah relatif komplek conjugate sifat dielektrik pada fase kontinu dan disperse. Sementara $\phi$ adalah volume fraksi fase dispersi dan $\mathrm{a}=2$ untuk disperse bola dan $\mathrm{a}=1$ untuk disperse silinder, serta o/w emulsi.

Untuk fluida minyak (water-oil emulsi) ekspresi efektif dielektrik adalah

$$
\ln \kappa^{*}=\phi \ln \kappa_{D}^{*}+(1-\phi) \ln \kappa_{C}^{*}
$$

\section{METODOLOGI}

Pada pemodelan ini diasumsikan menggunakan magnetron sebagai sumber pembangkit gelombang mikro, beroperasi pada frekuensi 2,45 GHz, dengan tipe MICRO DENSHI UM1500 yang berdaya1.5 kW [10] dan MEGA LP 320 yang berdaya $500 \mathrm{~W}$ [11], pada modus $\mathrm{TE}_{11}$. Gelombang akan ditransmisikan sepanjang arah sumbu $\mathrm{Z}$ melalui pandu gelombang silindrik sepanjang $1000 \mathrm{~m}$, dengan diameter 4 inci, dengan kedalaman minyak mentah pada $20 \mathrm{~cm}$ bertemparatur $200^{\circ} \mathrm{C}$.

Metode pemodelan pemanasan fluida diturunkan dari model fisik parametrik dengan alasan setiap perbedaan sifat dielektrik dapat menghasilkan persamaan pemodelan yang berbeda. Hal ini dapat dilakukan melalui pendekatan beberapa fungsi [12].

1. Fungsi linear dan parabolik (kuadratik)

$$
\frac{\epsilon^{\prime \prime}}{\epsilon_{\circ}}=A+2 B T+C T^{2}
$$

2. Fungsi eksponensial

$$
\begin{aligned}
& \frac{\epsilon^{\prime \prime}}{\epsilon_{\circ}}=C e^{\gamma T} \\
& \frac{\epsilon^{\prime \prime}}{\epsilon_{\circ}}=A e^{-\beta\left(T-T_{\circ}\right)^{2}}
\end{aligned}
$$

3. Fungsi kombinasi eksponensial

$$
\frac{\epsilon^{\prime \prime}}{\epsilon_{\circ}}=A e^{-\beta\left(T-T_{\circ}\right)^{2}}+C e^{\gamma T}
$$

4. Fungsi polynomial orde tinggi

$$
\frac{\epsilon^{\prime \prime}}{\epsilon_{\circ}}=A T^{m}+B T^{n}
$$

Perumusan persamaan pemodelan pemanasan ditentukan dari persamaan pemanasan fluida menggunakan energi gelombang mikro serta bentuk numeriknya sebagaimana persamaan-persamaan berikut:

$$
\begin{aligned}
\frac{\partial T}{\partial t}+\vec{\nu} \nabla T & =\frac{k}{\rho C_{p}} \nabla^{2} T+\frac{Q}{\rho C_{p}} \\
Q & =2 \pi f \epsilon_{\circ} \epsilon_{r}(\tan \delta)|E|^{2} \\
\vec{E} & =\frac{1}{N} \sum E^{\tau} \\
\frac{T_{i, j, k, t}^{k+1}-T_{i, j, k, t}^{k}}{T_{i, j, k, t}^{k}} & \leq 10^{-6}
\end{aligned}
$$

Langkah-langkah pemodelan adalah sebagai berikut:

1. Pertama adalah menentukan model dan dimensi cavity sebagai tempat minyak mentah di dalam pandu gelombang silinder. Cavity dipilih berbentuk silinder sebagaimana bentuk sumur minyak bumi, dengan diameter 4 inchi $(10,16 \mathrm{~cm})$ dan panjang $1000 \mathrm{~m}$. Diasumsikan di dalamnya berisi fluida minyak mentah dengan 
kondisi awal berada pada temperatur $100^{\circ} \mathrm{F}\left(37,78^{\circ} \mathrm{C}\right)$ dan viskositas sebesar 33,11 cp. Parameter fisik lainnya adalah konduktivitas termal, massa jenis, kalor jenis minyak mentah masing-masing adalah $0,168 \mathrm{Wm}^{-1}$ ${ }^{\circ} \mathrm{C}^{-1}, 900 \mathrm{kgm}^{-3}, 2000 \mathrm{Wskg}^{-1}{ }^{\circ} \mathrm{C}^{-1}$. Konstanta dielektrik dan loss dielektrik berturut-turut adalah 2,8 dan 0,15,dan diprediksi pada kedalaman $20 \mathrm{~cm}$ temperatur minyak mentah masih mencapai sekitar $200^{\circ} \mathrm{C}$ [4].

2. Kedua adalah menentukan model persamaan pembangkit panas lokal $Q=2 \pi f \epsilon_{\circ} \epsilon_{r}(\tan \delta)|E|^{2}$ dengan nilai loss factor dielektrik tan $\delta$, dipilih satu dari lima persamaan sebagaimana model pada Pers.(16) sampai (20) sesuai data sekunder yang telah diperoleh dengan cara melakukan fitting data danmengujinya melalui program matlab. Sehingga diperoleh persamaan Q sebagai fungsi temperatur, konstanta dan loss factor dielektrik.

3. Ketiga adalah menentukan model perambatan panas sesuai persamaan $\frac{\partial T}{\partial t}+\vec{\nu} \nabla T=\frac{k}{\rho C_{p}} \nabla^{2} T+\frac{Q}{\rho C_{p}}$ dengan nilai $\mathrm{Q}$ mengikuti hasil yang diperoleh pada langkah ketiga. Sehingga akanmendapatkan solusi persamaan distribusi temperatur sebagai fungsi posisi dan waktupada koordinat silinder.

4. Keempat adalah membuat diagram dan grafik hasil persamaan model perambatan panas dalam tiga dimensi pada koordinat silinder.

Hasil simulasi berupa grafik kurva tiga dimensi sebagaimana persamaan model perambatan panas yang telah diperoleh, yaitu merupakan persamaan distribusi temperatur di sepanjang model silinder sebagai fungsi posisi dan waktu.

Analisis Error dilakukan untuk menentukan tingkat kebenaran pemodelan yang diperoleh. Metode analisa data menggunakan parameter NSD (Normalisasi Square Deviation) sebagaimana rumus berikut:

$$
N S D=\frac{\int_{\propto}^{\propto}\left|Q_{A}(T, t)-Q_{s}(T, t)\right|^{2} d t}{\int_{\propto}^{\propto}\left|Q_{s}(T, t)\right|^{2} d t}
$$

dengan $\mathrm{Q}_{A}(\mathrm{~T}, \mathrm{t})$ adalah solusi eksak dan $\mathrm{Q}_{s}(\mathrm{~T}, \mathrm{t})$ adalah solusi pemodelan dari Pers.(2). Nilai NSD $\leq 10^{-3}$ untuk menentukan kelayakan fungsi matlab.

Untuk tingkat error dipilih sekitar 0-15\% sehingga tingkat kebenaran model sebesar $85-100 \%$. Final model ditampilkan dalam bentuk persamaan model pemanasan beserta grafik atau kurva fitting, antara kurva dari data asli dengan kurva hasil pemodelan. Hal ini menunjukkan final model sebagai representasi model akhir pemanasan gelombang mikro.

\section{HASIL DAN PEMBAHASAN}

Hasil pemodelan fungsi absorbsi menggunakan matlab menunjukkan pendekatan persamaan berbentuk linear bervariasi terhadap temperatur sebagaimana bentuk persamaan dielektrik $\epsilon^{\prime}=0,0048 \mathrm{~T}+2,7769$ dengan standar deviasi 0,014 dan persamaan $\frac{\epsilon^{\prime \prime}}{\epsilon^{\prime}}=\tan \delta=0,0007 \mathrm{~T}+0,2791$ dengan standar deviasi sebesar 0,004 . Dengan grafik kurve fitting sebagaimana ditunjukkan Gambar 2. sedangkan pendekatan eksponensial menunjukkan hasil persamaan $\epsilon^{\prime}=\exp (1,0217+0,0016581 \mathrm{~T})$ dengan standar deviasi 0,015 dan $\frac{\epsilon^{\prime \prime}}{\epsilon^{\prime}}=\exp (-1,2759+0,0022313 \mathrm{~T})$ dengan standar deviasi 0,004 . Grafik kurve fitting ditunjukkan pada Gambar 3.

Selanjutnya dari nilai ini dihitung besar heat generation $\mathrm{Q}$ $=(0,0324 \mathrm{~T}+13,641) \mathrm{Wm}^{-3}$. Nilai ini kemudian dihitung deviasinya melalui parameter NSD sebagaimana Pers.(23) untuk mendapatkan kelayakan fungsi pendekatan. Sehingga untuk pendekatan fungsi linear orde satu diperoleh nilai NSD sebesar 0,000143277. Hal ini berarti fungsi tersebut layak sebagai fungsi pemodelan karena nilainya kurang dari 0,001.

Setelah mengetahui besarnya daya yang dirambatkan di dalam pandu gelombang yang berisi minyak, minyak mentah, dan besarnya heat generation maka dapat dibuat pemodelan persamaan distribusi temperatur menggunakan Pers.(21)

$$
\frac{\partial T}{\partial t}+\vec{\nu} \nabla T=\frac{k}{\rho C_{p}} \nabla^{2} T+\frac{Q}{\rho C_{p}}
$$

melalui program Matlab persamaan perpindahan panas fungsi parabolik pada koordinat silinder. Asumsi pada pemodelan ini adalah gerakan fluida konstan, sehingga suku kedua persamaan ruas kiri dapat diabaikan. Distribusi temperatur pada koordinat silinder merupakan pengembangan Pers.(21) dengan mengganti heat generasi Q menjadi fungsi linear sehingga persamaan menjadi

$$
\frac{\partial T}{\partial t}=K\left(\frac{1}{r} \frac{\partial T}{\partial r}+\frac{\partial^{2} T}{\partial r^{2}}+\frac{1}{\partial r^{2}} \frac{\partial^{2} T}{\partial \theta^{2}}+\frac{\partial^{2} T}{\partial z^{2}}\right)+B T
$$

dengan $\mathrm{K}=\frac{k}{\rho C_{p}}$ dan $\mathrm{B}=\frac{Q}{\rho C_{p}}$.

Solusi numerik persamaan ini dapat diselesaikan menggunakan transformasi koordinat $\eta=\ln r$ sehingga diperoleh persamaan berikut

$$
\frac{\partial T}{\partial t}=K\left(\frac{1}{r^{2}}\left(\frac{\partial^{2} T}{\partial \eta^{2}}+\frac{\partial^{T}}{\partial \theta^{2}}\right)+\frac{\partial^{2} T}{\partial z^{2}}\right)+B T
$$

Dengan mengubah bentuk persamaan differensial untuk orde satu menjadi bentuk persamaan diskrit melalui substitusi berikut ini

$$
\frac{\partial T}{\partial t}=\frac{T_{k+1}-T_{k}}{\Delta t}
$$

dan persamaan differensial untuk orde kedua dalam bentuk diskrit menjadi

$$
\frac{\partial^{2} T}{\partial t^{2}}=\frac{T_{k+1}-2 T_{k}+T_{k+1}}{\Delta t}
$$

serta menggunakan pendekatan central difference untuk persamaan differensial orde dua pada ruas kanan dan forward difference untuk persamaan differensial orde pertama pada ruas kiri, sehingga diperoleh persamaan perbedaan menjadi lebih sederhana sebagaimana persamaan berikut 

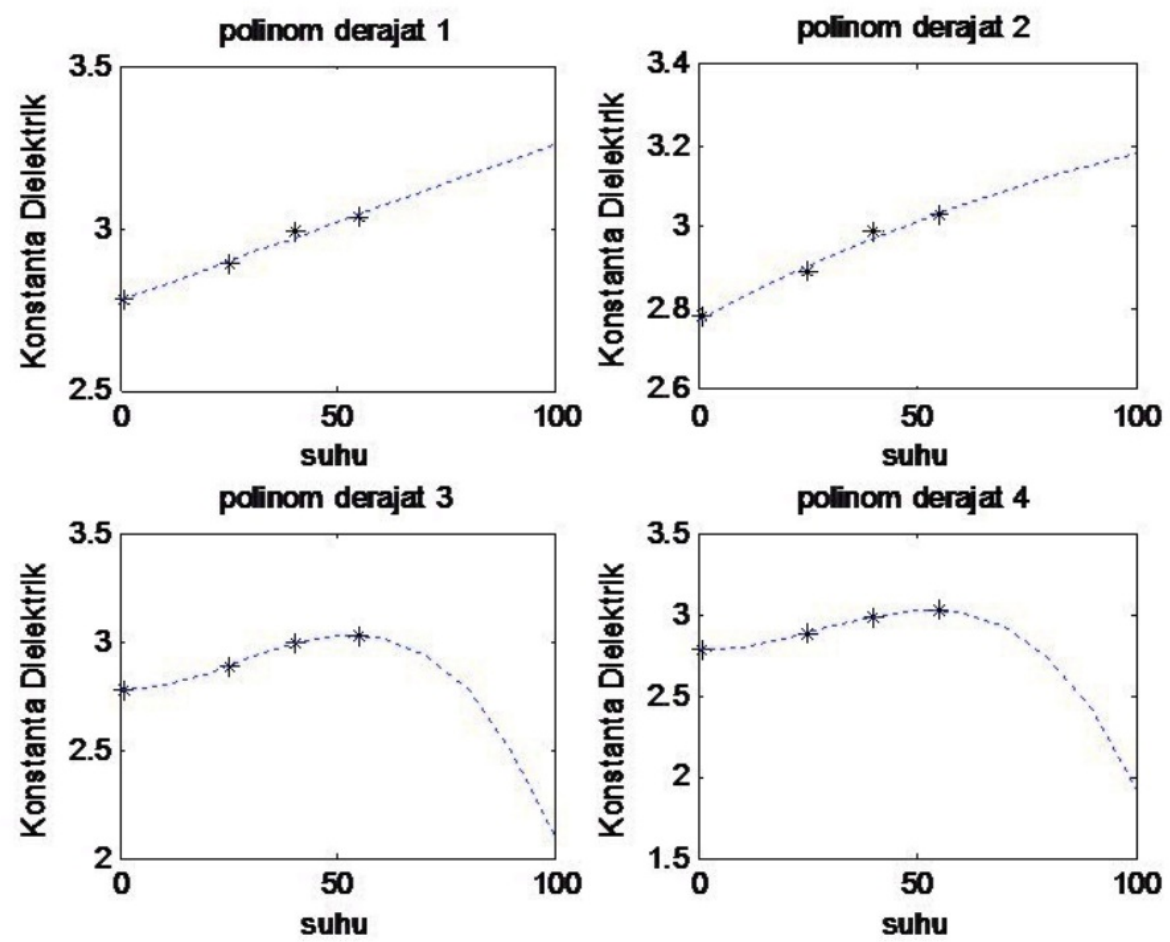

Gambar 2: Grafik curve fitting pendekatan linear.

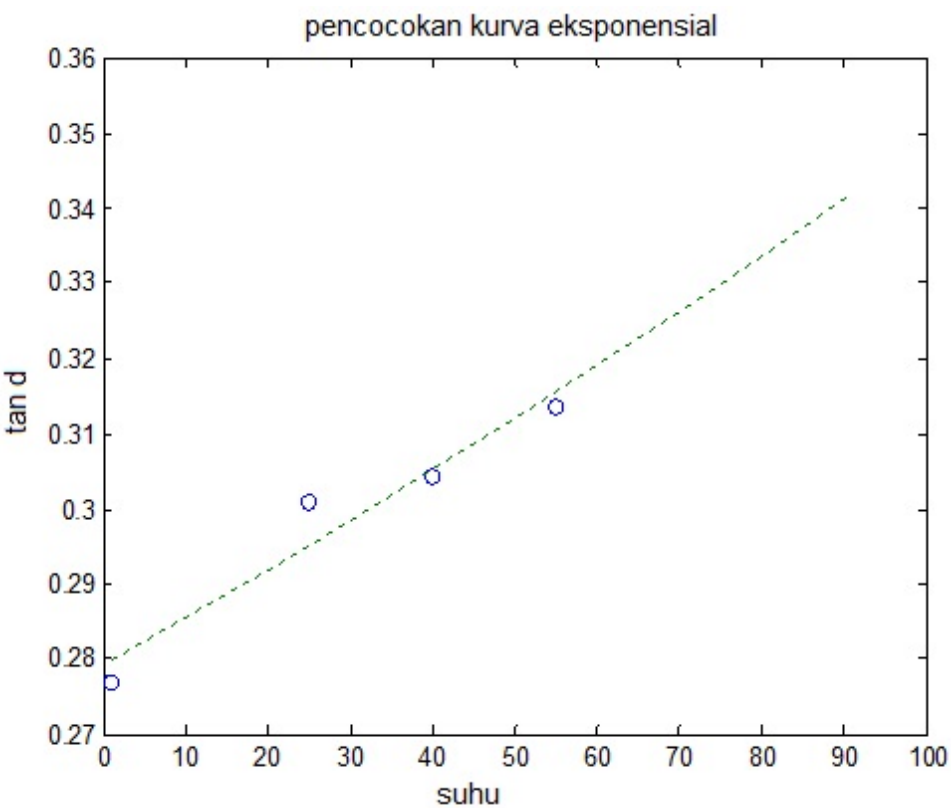

Gambar 3: Grafik curve fitting pendekatan eksponensial.

$\frac{T_{i, j}^{k+1}-T_{i, j}^{k}}{\Delta t}=\frac{K}{r^{2}}\left(\frac{T_{i, j+1}^{k}-2 T_{i, j}^{k}+T_{i, j-1}^{k}}{(\Delta \eta)^{2}}\right)+K\left(\frac{T_{i+1, j}^{k+1}-2 T_{i, j}^{k+1}+T_{i-1, j}^{k+1}}{(\Delta z)^{2}}\right)+B T_{i, j}^{k}$ 


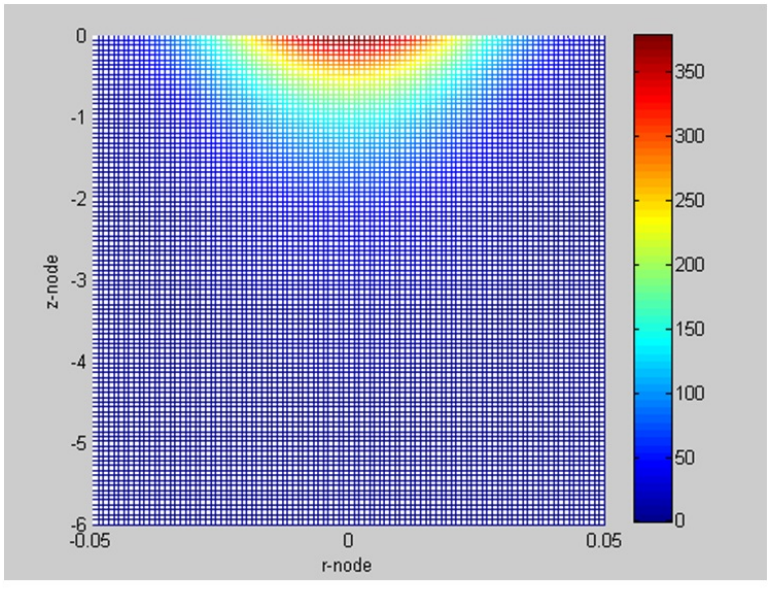

Gambar 4: Distribusi temperatur untuk daya 500W.

dengan $\mathrm{T}$ menyatakan temperatur pada suatu titik dengan indeks $\mathrm{i}, \mathrm{j}, \mathrm{k}$ berkorelasi dengan suatu tititk pada koordinat silinder $\mathrm{r}, \mathrm{Z}, \mathrm{t}$ yang berarti posisi titik pada jari-jari r, kedalaman $\mathrm{z}$ dan waktu t. Sedangkan $\Delta t, \Delta \eta, \Delta z$ masing-masing adalah ukuran langkah waktu, jari-jari (dalam fungsi ln), dan kedalaman.

Kemudian untuk menentukan kondisi pada syarat perbatasan digunakan beberapa asumsi agar diperoleh keadaan yang sesuai dengan keadaan yang diharapkan antara lain adalah pada perbatasan antara udara dan minyak mentah, minyak mentah, temperatur dipermukaan minyak adalah seki$\operatorname{tar} 400^{\circ} \mathrm{C}$. Keadaan ini ditentukan berdasarkan pada perhitungan analitis konversi energi yaitu perubahan energi radiasi gelombang mikro menjadi energi panas yang diserap secara langsung oleh minyak tanpa melalui perantara medium, sementara pipa tempat minyak masih berada pada kondisi semula.

Berdasarkan mekanisme transfer panas tersebut maka digunakan syarat batas sebagai fungsi eksponensial yang berubah terhadap sumbu $\mathrm{z}$ atau pada kedalaman sumur. Sementara untuk perambatan panas kearah radial menggunakan fungsi cosinus yang berubah terhadap sumbu $R$ atau jari-jari.

Simulasi ini menggunakan persamaan kondisi awal yaitu persamaan $\mathrm{T}=400 \cos (\mathrm{r}) \exp (\mathrm{z})$ dan menggunakan persamaan syarat batas yaitu $\mathrm{T}=40 \exp \left(\frac{r}{t}-40 \cos (\mathrm{rt})\right)$.

Persamaan ini dipilih berdasarkan keadaan yang terjadi di lapangan sebagaimana hasil penelitian bahwa di dalam pipa di sekitar sumber gelombang mikro merupakan fungsi eksponensial terhadap sumbu $\mathrm{z}$ atau pada arah kedalaman pipa dan merupakan persamaan kosinus untuk arah pada sumbu $r$.

Berdasarkan persamaan tersebut kemudian dituangkan dalam script Matlab pada M-file, dan dijalankan dengan beberapa kondisi awal dan syarat batas. Salah satu hasil pemrograman dan menjalankan script tersebut pada rentang jari-jari adalah $-0,05<\mathrm{r}<0,05$ sementara rentang kedalaman adalah $0<\mathrm{z}<6$ dimana tetapan $\mathrm{K}=9,33 \times 10^{-8}, \mathrm{~B}=8,56$ $\times 10^{-6}$, diperoleh grafik distribusi temperatur sebagaimana ditampilkan pada Gambar 4.

\section{SIMPULAN}

Berdasarkan hasil penelitian ini dapat disimpulkan bahwa pemanasan minyak mentah menggunakan energi gelombang mikro dimungkinkan untuk dilakukan sebagai salah satu pengganti sumber energi konvensional steam injection. Hasil pemodelan menunjukkan bahwa untuk fungsi absorbsi dapat didekati dengan baik melalui pendekatan fungsi linear sebagaimana fungsi absorbsi untuk petroleum.
[1] A.S. Hidayat, Konsumsi BBM dan Peluang Pengembangan Energi Alternatif, Inovasi Perhimpunan Pelajar Indonesia Jepang, pp. 11-17, 2005.

[2] T, Dartanto, BBM, Kebijakan Energi, Subsidi, dan Kemiskinan di Indonesia, Inovasi Perhimpunan Pelajar Indonesia Jepang, pp. 3-10, 2005.

[3] B. Hascakir, C. Acar, and S. Akin, Energy Fuels, 23(12), 60336039 (2009).

[4] T. Basak, AIChE Journal, 50, 2659-2675 (2004).

[5] A. Sahni, M. Kumar, and R.B.Knapp, Electromagnetic Heating Methods for Heavy Oil Reservoirs, Soc. Pet. Eng. SPEAAPG, 2000.

[6] N. Bjorndalen, and M.R. Islam, J.Pet.Sci.Eng., 43(3-4), 139-150 (2004).

[7] D. Salvi, et al., J. Microw. Power Electromagn. Energy, 44, 187-
197 (2010).

[8] J.D. Jackson, Classical Electrodynamics (Third Edition, John Wiley \& Son, 1998).

[9] P. Ratanadecho, K. Aoki, and M. Akahori, Appl. Math. Model., 26, 449-472 (2002).

[10] P. Ratanadecho, K. Aoki, and M. Akahori, A numerical and experimental investigation of the modeling of microwave heating for liquid layers using a rectangular wave guide (effects of natural convection and dielectric properties), 2002.

[11] O. Gizem Gunal and M.R. Islam, J. Pet. Sci. Eng., 26(1-4), 263 272 (2000).

[12] J.M. Hill, and M.J. Jennings, Appl Math Model., 17, 369 (1993). 